\title{
Fabrication of Hollow Metal Microcapsules with Mesoporous Shell Structure: Application as Efficient Catalysts Recyclable by Simple Magnetic Separation
}

\author{
Da Young Jang, Hyung Gyu Jang, Gye Ryung Kim, and Geon-Joong Kim \\ Department of Chemical Engineering, Inha University, Incheon 402-751, Korea. *E-mail: kimgj@inha.ac.kr \\ Received June 13, 2011, Accepted July 19, 2011
}

\begin{abstract}
Monodispersed porous $\mathrm{NiO}$ and $\mathrm{Co}_{3} \mathrm{O}_{4}$ microcapsules with a hollow core were synthesized using SBA-16 silica sol and PS as a hard template. The porous hollow microcapsules were characterized by XRD, TEM and $\mathrm{N}_{2}$ adsorption/desorption analysis. After $\mathrm{H}_{2}$ reduction of metal oxide microspheres, they were conducted as an active catalyst in the reduction of chiral butylronitrile and cyanobenzene. The mesoporous metals having a hollow structure showed a higher activity than a nonporous metal powder and an impregnated metal on the carbon support.
\end{abstract}

Key Words : Hollow porous metal, Replication, Microcapsules, Asymmetric reaction

\section{Introduction}

The core-shell type microcapsules show various unique properties owing to their well-defined structures. They are applicable to a wide variety of materials such as catalyst support, electronics and biologically active agents. ${ }^{1-6}$ Formation of porosity in the egg shell of microcapsules having macroporous hollow core could add more advantages in application. Consequently, some recent research efforts have been paid to the synthesis of spherical hollow particles with a narrow size distribution. ${ }^{7-18}$ In a typical procedure, inorganic hollow microspheres can be fabricated by sacrificial core method for which nano-sized inorganic particles are coated on the surfaces of polymer spheres by controlled precipitation of inorganic precursor molecules. The template polymers are subsequently removed by selective dissolution in the proper solvents or by calcination in air to generate the inorganic hollow spheres. ${ }^{18-21}$

The synthesis of organized mesoporous materials has stimulated extensive research over the past decade. ${ }^{22-27}$ In particular, mesoporous materials with a transition-metal oxide framework have immense potential for applications as catalysts, sensors, and electrode materials because of their characteristic properties. For selective applications, the potential can only be maximized through the highly crystalline state. High thermal and mechanical stabilities are associated with the crystalline state. The changes in the crystal structure with a subsequent loss of porosity may happen generally in converting the amorphous walls of as made materials to crystalline forms at higher temperatures. Despite considerable progress in the synthetic field of porous solids, major challenges remain for fabricating the ordered mesoporous structures with high metal content by using the co-assembly of macromolecular surfactants and inorganic species. An early route to preparing mesoporous metals involves the dealloying of a less noble metal from a bimetallic alloy such as Raney nickel and other metals. ${ }^{28}$ Dealloying processes provide limited control over structural parameters such as pore geometry and order. In contrast, block copolymer self-assembly or templating with metal species provides access to highly ordered structures. Metals with two- or three-dimensional nanostructures are expected useful in applications. We have recently fabricated ordered mesoporous metal replica with hexagonally ordered mesopore channels by using ordered mesoporous silica (SBA-15 or -16) as a mold. ${ }^{29}$ Porous metals can be considered as fundamental candidates for raw materials of active catalysts. Though various semiconductors and metals with uniform structures have been exploited, the synthesis and application of hollow type mesostructured metals as a catalyst are rarely reported. Furthermore, the method for the fabrication of nonporous hollow type metal oxide spheres has been reported mainly in the literature until now. In this respect, a general synthetic strategy for mesostructured hollow metals guided by host-guest chemistry is much desired. Herein the fabrication of metal oxide and pure metal microcapsules with hollow macroporous core and mesoporous shell structure will be presented. We synthesized the hollow metal oxide and pure metal microcapsules having mesopores in the shell via reverse replication method using porous silica hollow capsules as a mold. Those mesoporous metals were employed as catalysts in the reduction of chiral butylronitrile and cyanobenzene to evaluate their catalytic activities. In the catalytic reduction, the mesoporous metals showed higher activity than a nonporous metal powder and an impregnated metal on the carbon support.

\section{Experimental}

SBA-16 Sol Coating on PVP Modified PS. The silica sol for SBA-16 was prepared according to the method reported previously in the literature. ${ }^{18,29}$ The triblock copolymer, Pluronic F-127 (Aldrich), was used as a surfactant and tetraethylorthosilicate (TEOS, 98\%, Alchich) as a silica source, respectively. The starting composition in molar ratio for the synthesis of high grade SBA-16 sol was fixed as 1.0 

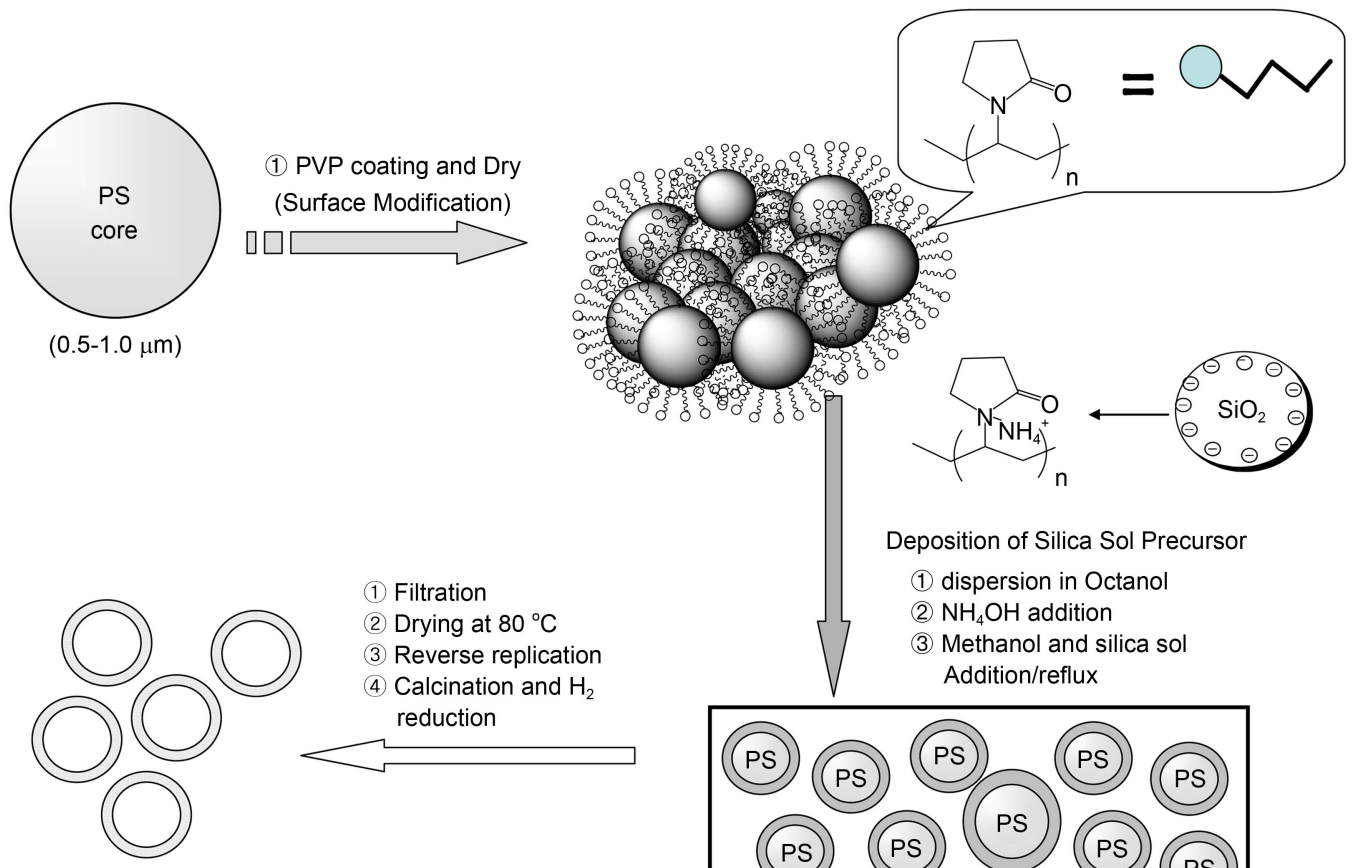

Hollow type Metals

with mesoporous shells

Deposition of Silica Sol Precursor

(1) dispersion in Octanol

(2) $\mathrm{NH}_{4} \mathrm{OH}$ addition

(3) Methanol and silica sol Addition/reflux

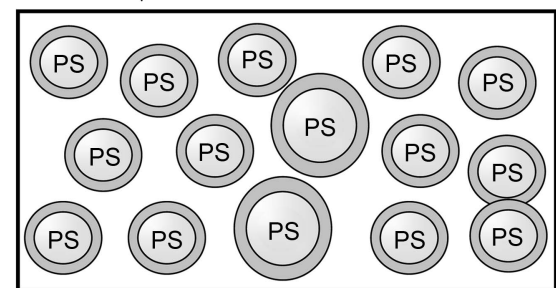

Scheme 1. Fabrication of mesoporous metals using PS template and SBA-16 silica-sol by sacrificial core method.

TEOS: 0.011 F-127: 10.1 Ethanol: $0.24 \mathrm{HCl}: 10 \mathrm{H}_{2} \mathrm{O}$. This sol was coated on the surfaces of PS microspheres for the synthesis of silica, metal oxide and metal microcapsules with hollow macroporous core/mesoporous shell structure in a narrow particle size distribution. The procedure to fabricate the hollow microcapsule of metals is shown briefly in Scheme 1. The polystyrene (PS) with a size distribution in 0.5-1.0 micrometer scale was used as a template core in the synthesis. First of all, PS polymer was coated by polyvinylpyrollidone (PVP) at the amount of $10 \mathrm{wt} \%$. This sample was dried at $80^{\circ} \mathrm{C}$ under vacuum for $12 \mathrm{~h}$. The PVPmodified PS particles (2.0 g) were dispersed in the solution of octanol $(10 \mathrm{~mL})$ and ammonia water $(0.3 \mathrm{~mL})$ with stirring for $0.5 \mathrm{~h}$, and SBA-16 sol $(8 \mathrm{~mL})$ was added dropwise to the suspended solution. Then methanol $(60 \mathrm{~mL})$ was additionally introduced into the mixture. Deposition of silica sol to form the mesoporous shells has been performed for 6 $\mathrm{h}$ under a vigorous stirring at $50{ }^{\circ} \mathrm{C}$. The silica sol coated PS composite was filtered, dried at $100{ }^{\circ} \mathrm{C}$ for $48 \mathrm{~h}$, and then the block copolymer F127 in the pore of as-synthesized hollow silica was extracted in the refluxing methanol solvent (300 $\mathrm{mL})$ acidified with $\mathrm{HCl}(35 \%, 2 \mathrm{~mL})$.

Synthesis of Mesoporous Hollow Metal Oxide and Metal Microcapsules. The replication of mesoporous silica by infiltration of pores with corresponding metal salts has been conducted for the synthesis of metal oxide replica of hollow capsules, as shown in Scheme 2. The solution of Cobalt(II) nitrate $\left(\mathrm{Co}\left(\mathrm{NO}_{3}\right)_{2}, 97 \%\right.$, Aldrich) and Nickel(II) nitrate $\left(\mathrm{Ni}\left(\mathrm{NO}_{3}\right)_{2}, 97 \%\right.$, Aldrich) dissolved in ethanol were incorporated into the pores of calcined porous silica microcapsules by incipient wetness method, respectively. As a typical method, $1 \mathrm{~g}$ of silica spheres was added to a solution obtained by dissolving $0.6 \mathrm{~g}$ of $\mathrm{Co}\left(\mathrm{NO}_{3}\right)_{2}$ or $\mathrm{Ni}\left(\mathrm{NO}_{3}\right)_{2}$ in ethanol $(2.5 \mathrm{~mL})$. The mixture was evaporated to remove the solvent by heating at $80^{\circ} \mathrm{C}$ under vacuum. The powder sample was dried at $100{ }^{\circ} \mathrm{C}$ for $12 \mathrm{~h}$ for filling the pores by

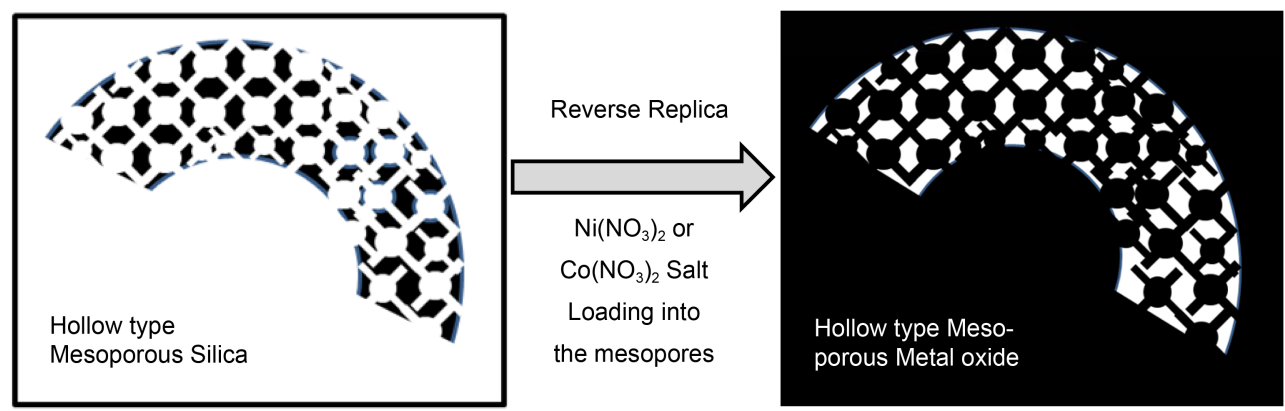

Scheme 2. Concept for microcapsule formation of mesoporous $\mathrm{NiO}$ and $\mathrm{Co}_{3} \mathrm{O}_{4}$ from hollow type mesoporous silica by reverse replication. 
metal salts completely, and heated in a muffle furnace from the room temperature to $600{ }^{\circ} \mathrm{C}$ with a heating rate of $1{ }^{\circ} \mathrm{C} /$ $\min$ to remove the PS templates in the core. The temperature was maintained at $600^{\circ} \mathrm{C}$ for $5 \mathrm{~h}$. The mesoporous $\mathrm{NiO}$ was obtained after dissolution of silica template by refluxing in $2 \mathrm{M} \mathrm{NaOH}$ for $2 \mathrm{~h}$. For $\mathrm{Co}_{3} \mathrm{O}_{4}$, the silica template was removed using an aqueous $10 \mathrm{wt} \% \mathrm{HF}$ solution. The porous metal oxide microcapsule products were recovered by filtration after washing with distilled water. The mesoporous oxides were reduced to their corresponding metals by $\mathrm{H}_{2}$ in the fixed bed type reactor at $450^{\circ} \mathrm{C}$ for $6 \mathrm{~h}$. The nonporous powder metal was also prepared by calcination of metal salt in air and following hydrogenation under hydrogen to use as a catalyst in comparison.

Characterization. X-ray powder diffraction (XRD) data were acquired on a D/MAX 2500V/PC diffractometer using $\mathrm{CuK \alpha}$ radiation. The morphology and microstructures of samples were characterized by field emission (FT) TEM (S4200), and FE-SEM (JEM-2100F). The nitrogen adsorption/ desorption analysis was performed at $-196{ }^{\circ} \mathrm{C}$ by using a surface area and porosity analyzer equipment (Micromeritics, ASAP 2010) to determine BET surface and the mean pore size.

Evaluation of Catalytic Activity. The catalytic activities of hollow type metal capsules were examined in the hydrogenation of (S)-4-chloro-3-hydroxybutyronitrile (S-CHB) and cyanobenzene, respectively. In the $\mathrm{H}_{2}$ hydrogenation of S-CHB, after dissolution of $2.0 \mathrm{~g}$ of S-CHB in methanol (40 $\mathrm{mL}), 0.5 \mathrm{~g}$ of metal catalyst was added to the solution. The mixture was stirred under the hydrogen pressure of $5-10 \mathrm{~kg} /$ $\mathrm{cm}^{2}$ at $30-90{ }^{\circ} \mathrm{C}$ for $24 \mathrm{~h}$ in the autoclave reactor. After removal of the metal catalyst by magnet from the product mixture, $1.5 \mathrm{~g}$ of $\mathrm{NaOH}$ was added and the mixture was stirred for $3 \mathrm{~h}$ at room temperature. The solvent was evaporated finally to give a (S)-3-pyrrolidinol-NaCl salt (SPD-salt). The yield of desired product was determined by weighting the isolated salt.

For the hydrogenation of cyanobenzene to produce benzyl amine, $0.5 \mathrm{~g}$ of metal catalyst was added into the mixed solution of methanol $(40 \mathrm{~mL})$ and cyanobenzene $(1.0 \mathrm{~g})$. The hydrogen pressure and the reaction temperature were controlled in the range of $3-10 \mathrm{~kg} / \mathrm{cm}^{2}$ and $30-90^{\circ} \mathrm{C}$, respectively. The products were analyzed by GC (HP 6890) equipped with a capillary column (HP-5, 5\% phenylmethyl siloxane) to determine the concentration of cyanobenzene and benzylamine.

\section{Results and Discussion}

Characterization of Materials. Figure 1 shows the SEM photographs of PS beads used as a hard template in this work. They have a narrow particle size distribution, showing the mean diameter of 0.5 and $1.0 \mu \mathrm{m}$, respectively. The prior modification of PS surfaces by coating a PVP polymer is critical for the successful deposition of hydrophilic precursor (inorganic sol) on the polymer surfaces.

The formation of mesopores in silica, $\mathrm{Co}_{3} \mathrm{O}_{4}, \mathrm{NiO}, \mathrm{Co}$ and
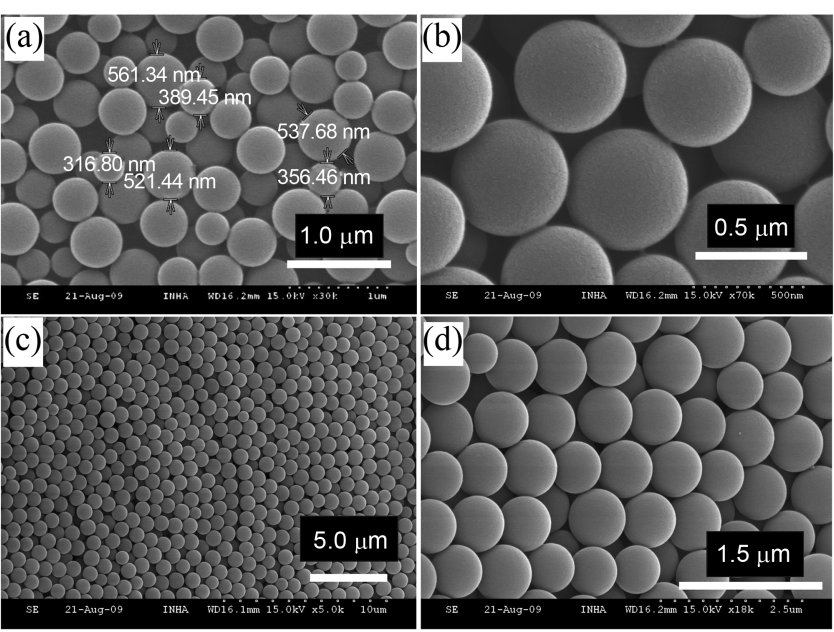

Figure 1. SEM images for PS micro beads used as a hard template for the fabrication of hollow mesoporous silica and metal microcapsules (a, b; $0.5 \mu \mathrm{m}, \mathrm{c}, \mathrm{d} ; 1.0 \mu \mathrm{m}$ in diameter)

Ni microspheres were determined by XRD, TEM and $\mathrm{N}_{2}$ adsorption analysis. In our previous work, the silica sample synthesized from the sol solution having the molar ratio of 1.0 TEOS: 0.011 F-127: 10.1 Ethanol: $0.24 \mathrm{HCl}: 10 \mathrm{H}_{2} \mathrm{O}$ exhibited the cubic structure, showing the well-resolved peaks at $2 \theta$ angles below $5^{\circ}$ in XRD patterns. However SBA-16 silica microcapsule fabricated in this study (as in Fig. 2) shows no peaks at the low angle of $2-5^{\circ}$, but one broad peak near $1.0^{\circ}$. This means the shell of hollow silica capsule is constructed by irregularly connected mesopores, due to lose in the ordering of cubic structure. The change of pore structure may be caused due to the addition of different solvent such as octanol as well as ammonia water. The wideangle-X-ray diffraction (XRD) results show the characteristic peaks that can be indexed as $\mathrm{Co}_{3} \mathrm{O}_{4}, \mathrm{NiO}$ and $\mathrm{Co}, \mathrm{Ni}$ metal phases (Fig. 2). The relative intensity and position of XRD peaks for our samples were exactly matched to those reported in the literature, respectively. ${ }^{30-36}$ The diffraction peaks can be assigned as corresponding planes of crystal

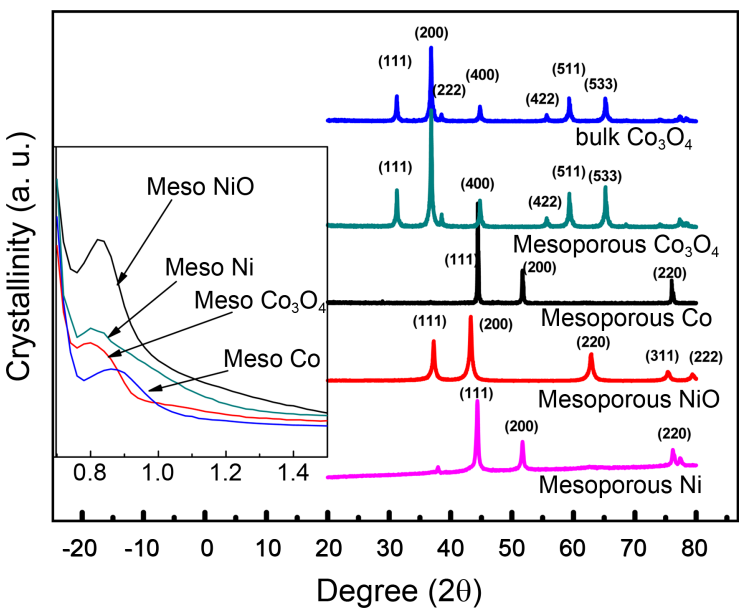

Figure 2. X-ray Diffraction patterns of mesoporous $\mathrm{Co}_{3} \mathrm{O}_{4}, \mathrm{NiO}$, $\mathrm{Ni}$ and Co metals. 

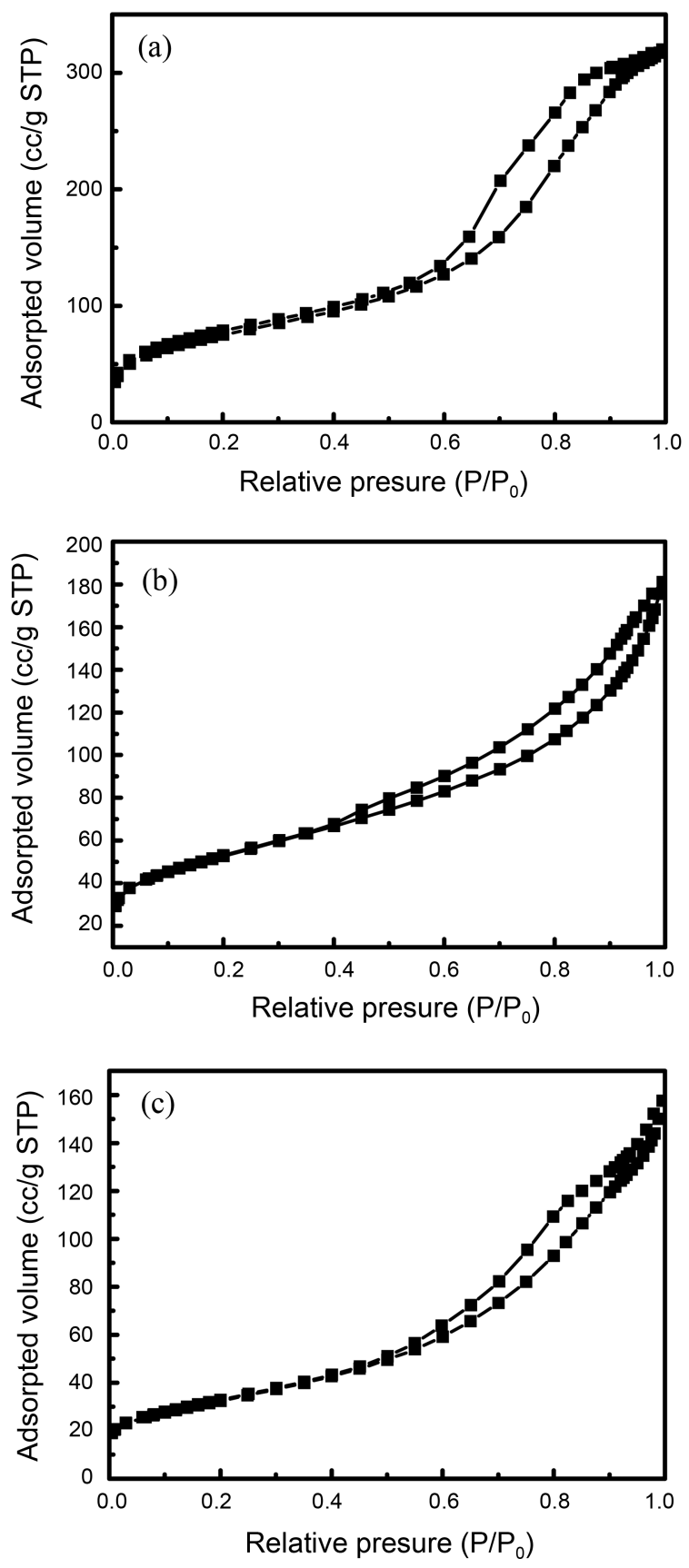

Figure 3. Nitrogen adsorption-desorption isotherms for hollow type mesoporous silica (a), mesoporous $\mathrm{NiO}(\mathrm{b})$ and $\mathrm{Co}_{3} \mathrm{O}_{4}(\mathrm{c})$.

lattice, as shown in Figure 2. However, it was observed that the mesoporous microcapsules of metal oxides and metals posses the same structure as the non-porous bulk particles.

The disordered arrangement of mesopores is also found in the shell wall of metal oxide and metal microspheres as similar as silica spheres in the x-ray diffractograms.

Figure 3 shows the nitrogen adsorption-desorption isotherms of the hollow-type porous silica and metal oxides. Their isotherms are type IV with a hysteresis loop, indicating the mesoporous property. The specific surface areas of mesoporous silica, $\mathrm{NiO}$ and $\mathrm{Co}_{3} \mathrm{O}_{4}$ microcapsules are 310 $\mathrm{m}^{2} / \mathrm{g}$ and $360 \mathrm{~m}^{2} / \mathrm{g}$, respectively. The mesopores with aver-

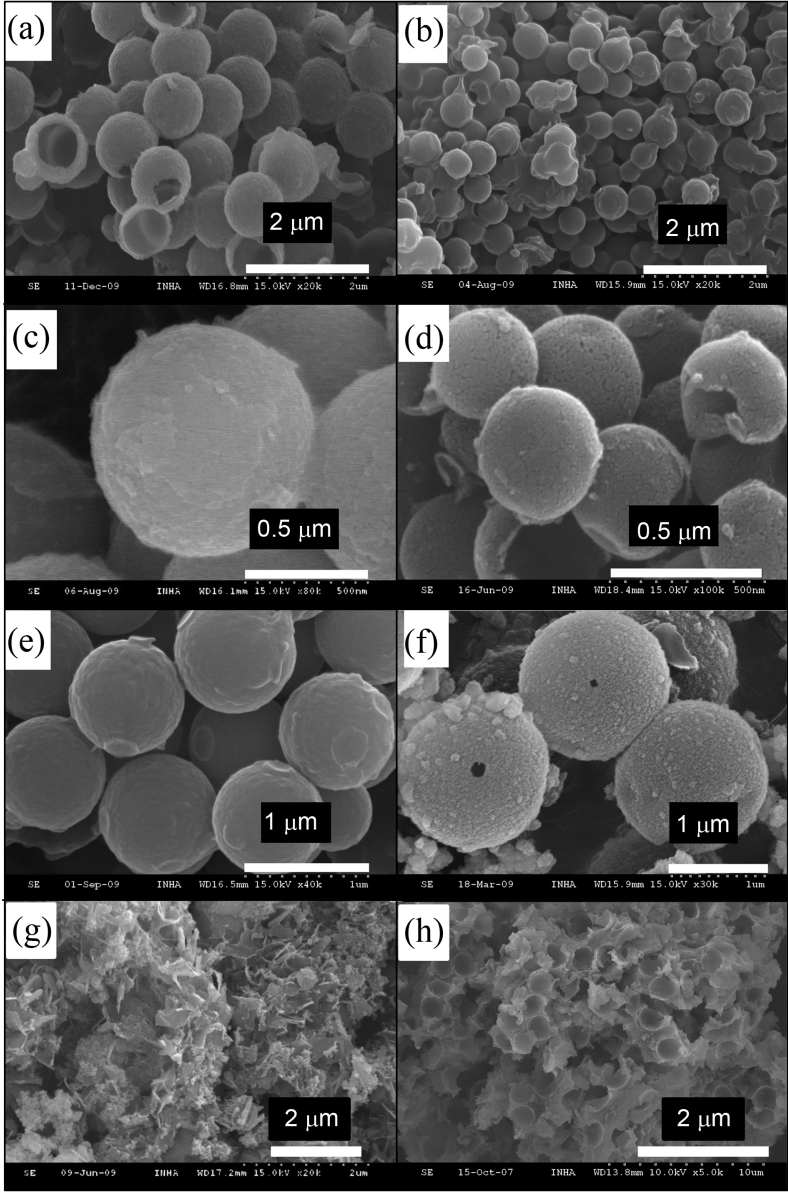

Figure 4. SEM images of hollow silica, metal oxides and corresponding metal microspheres. $(\mathrm{a}(1 \mu \mathrm{m}), \mathrm{b}(0.5 \mu \mathrm{m})$; mesoporous silica, (c); $\mathrm{NiO},(\mathrm{d}) ; \mathrm{Ni},(\mathrm{e}) ; \mathrm{Co}_{3} \mathrm{O}_{4}$, (f); Co metal, (g and h); silica, by using pure PS as a template without PVP addition)

age pore size of $40-45 \AA$ were formed inside the shell wall of silica and metal oxides.

Figure 4 shows the SEM images of various hollow type mesoporous silica, metal oxides and metal capsules fabricated using PS beads (diameter of 0.5 and $1 \mu \mathrm{m}$ ) as core templates, respectively. We found that the monodispersed micro-capsules could be synthesized very easily by reverse replication method. The calcination of PS template in air generated microcapsules having a hollow core with mesoporous shell. The hollow type mesoporous silica was remained after removal of core PS polymer by calcination at $600{ }^{\circ} \mathrm{C}$. As shown in Figure 4, a hollow structure with vacant core was clearly investigated in the photograph of Figure 4(a). The microscope image of calcined hollow silica (Fig. $4(a, b))$, metal oxides (c, e) and metal microcapsules $(d, f)$ also revealed the spherical shape with uniform size. The spherical shape of metal capsules was maintained perfectly during the reverse replication step and the selective dissolution of silica components. In addition, the oxide spheres were reduced into the corresponding metals under the $\mathrm{H}_{2}$ stream without a severe destruction in the spherical shapes as same as original silica capsules. As mentioned above, the prior modification of PS surfaces by PVP is important for 


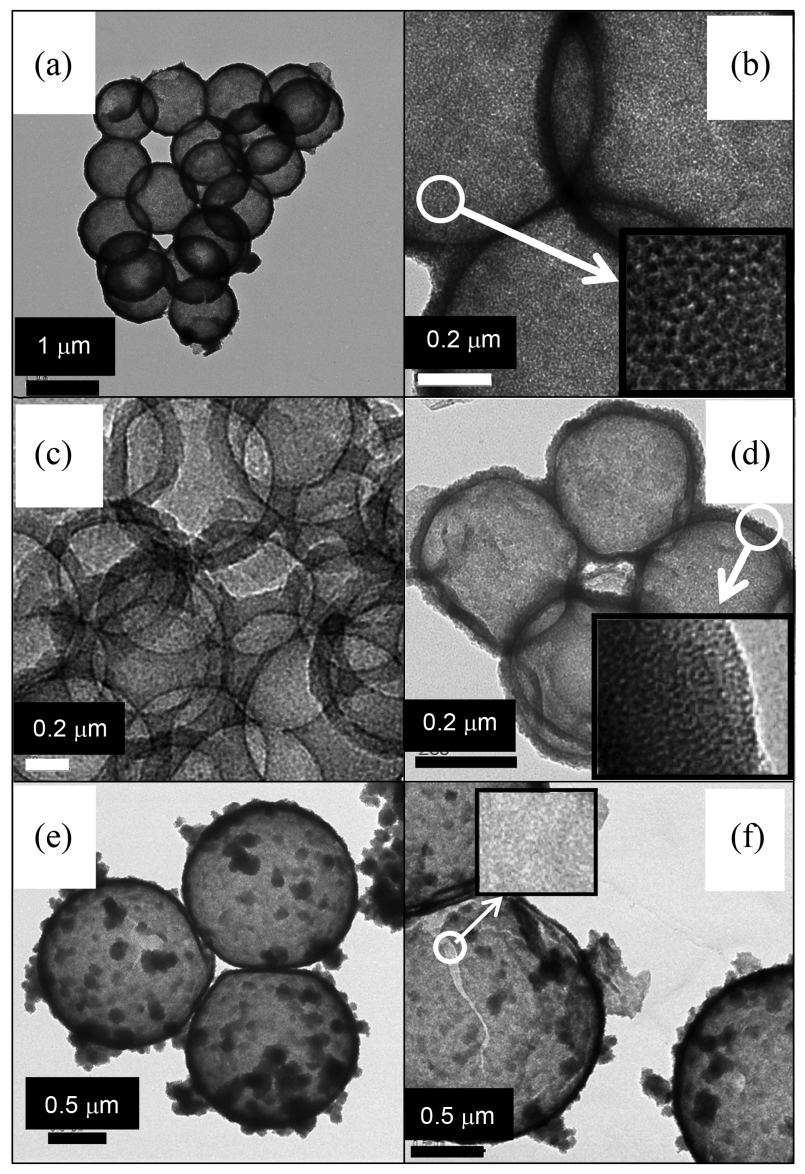

Figure 5. TEM images of of hollow silica, metal oxides and corresponding metal microspheres. ((a, b); mesoporous silica, (c); $\left.\mathrm{NiO},(\mathrm{d}) ; \mathrm{Ni},(\mathrm{e}) ; \mathrm{Co}_{3} \mathrm{O}_{4},(\mathrm{f}) ; \mathrm{Co}\right)$.

the successful coating of hydrophilic silica sol on the polymer surfaces. If the pure PS was used as a hard template for deposition of SBA-16 sol, only the aggregates of silica were obtained without the formation of hollow structures (Fig. 4(g)), and PS was embedded in the silica matrix, resulting in the vacant spherical void spaces after calcination, as can be seen in Figure 4(h).

TEM images revealed that the shape of calcined $\mathrm{SiO}_{2}$ and metal oxides microcapsules were spherical with nearly uniform size and thin shell walls. The shell of hollow core is composed of very small mesopores as found in the TEM images at high magnifications (Fig. 5(b), (d) and (f)). However the surfaces of hollow metal were covered with small particles after hydrogen reduction (e, f).

Evaluation of Catalytic Activities. In the catalytic reduction of the S-CHB, metal catalysts such as Raney metal, palladium and platinum can be used preferably to convert the cyano group into the primary amine. In this work, the mesoporous metal capsules were tested as a catalyst for the synthesis of S-PD-salt from the chiral S-CHB, and the results for the catalytic activity are listed in Table 1 . The hollow type porous $\mathrm{Ni}$ and $\mathrm{Co}$ metal microspheres gave much higher yield to S-PD-salt than the non-porous $\mathrm{Ni}$ and Co metal powder in the reduction of S-CHB by hydrogen. It
Table 1. Catalytic activities of mesoporous metals in the hydrogenation of chiral (S)-4-chloro-3-hydroxybutyronitrile to obtain the (S)-3-pyrrolidinol-NaCl salt (Temp.; $80{ }^{\circ} \mathrm{C}$ )

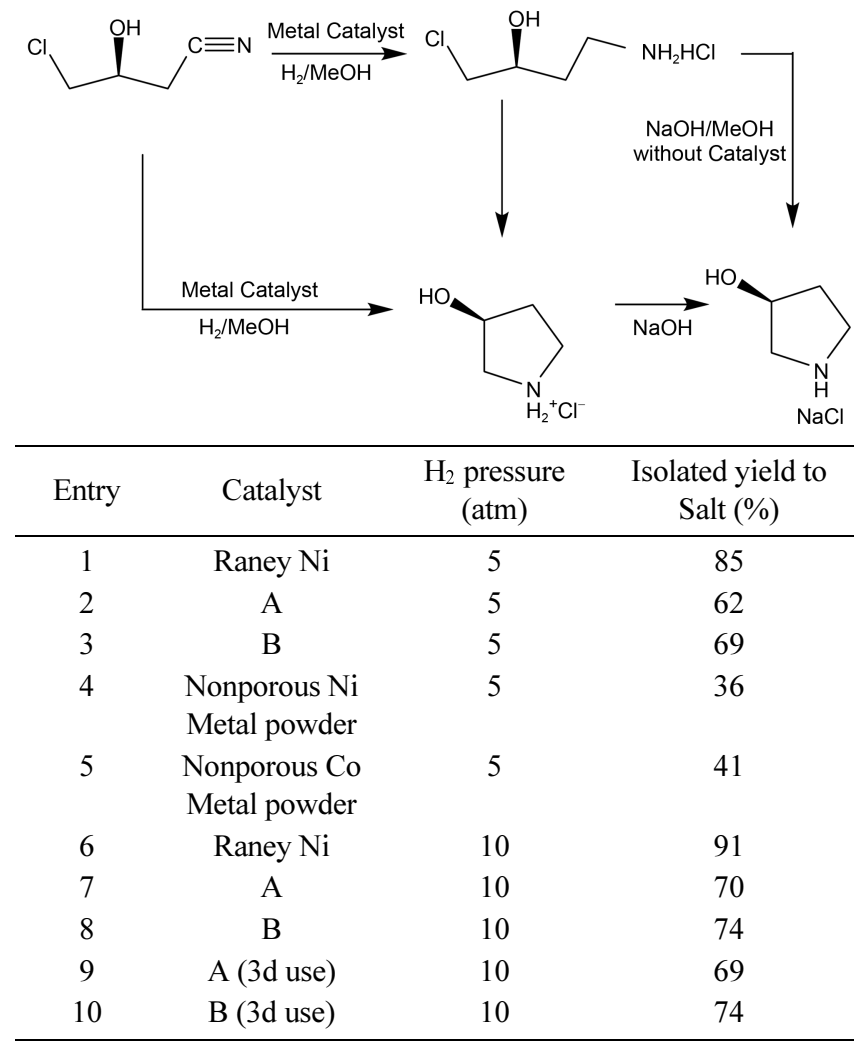

Catalyst amount; 0.5 g, S-CHB; 2.0 g. Catalyst A; mesoporous Ni microcapsule, Catalyst B; mesoporous Co microcapsule, Yield was calculated based on the starting (S)-CHB mole number.

is attributed to the pore structure with a large volume of metal capsules. The mesoporous Co catalyst showed slightly higher activity than Ni metal.

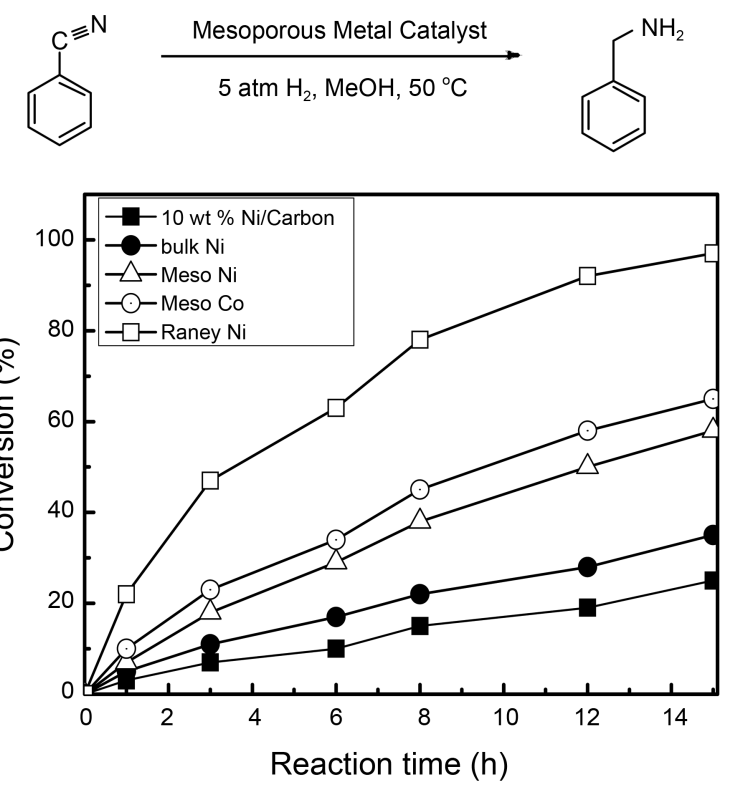

Figure 6. The catalytic activities of various metals in the hydrogenation of cyanobenzene. 
To investigate the effect of porous properties on the reduction activity, the hollow type metal catalysts were applied in the hydrogenation of cyanobenzene to benzylamine, and the results are shown in Figure 6. The porous Ni and Co metal spheres exhibited a higher catalytic activity than bulk metal powders. Furthermore, $10 \mathrm{wt} \% \mathrm{Ni}$ impregnated on the active carbon showed relatively low activity under the same reaction conditions. This result can be attributed to the higher metal surfaces exposed as compared to the bulk metal powders. The reduction was completed as the reaction time became prolonged for each case.

The effects of reaction temperature as well as $\mathrm{H}_{2}$ pressure were examined on the conversion of cyanobenzene in the catalytic reduction, and the obtained result is summarized in

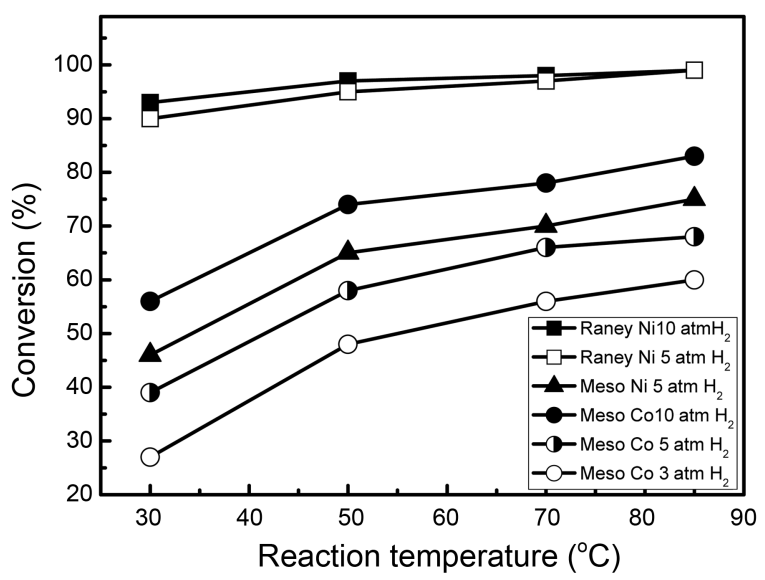

Figure 7. Effect of reaction temperature and $\mathrm{H}_{2}$ pressure on the catalytic activities of mesoporous metals in the hydrogenation of cyanobenzene.
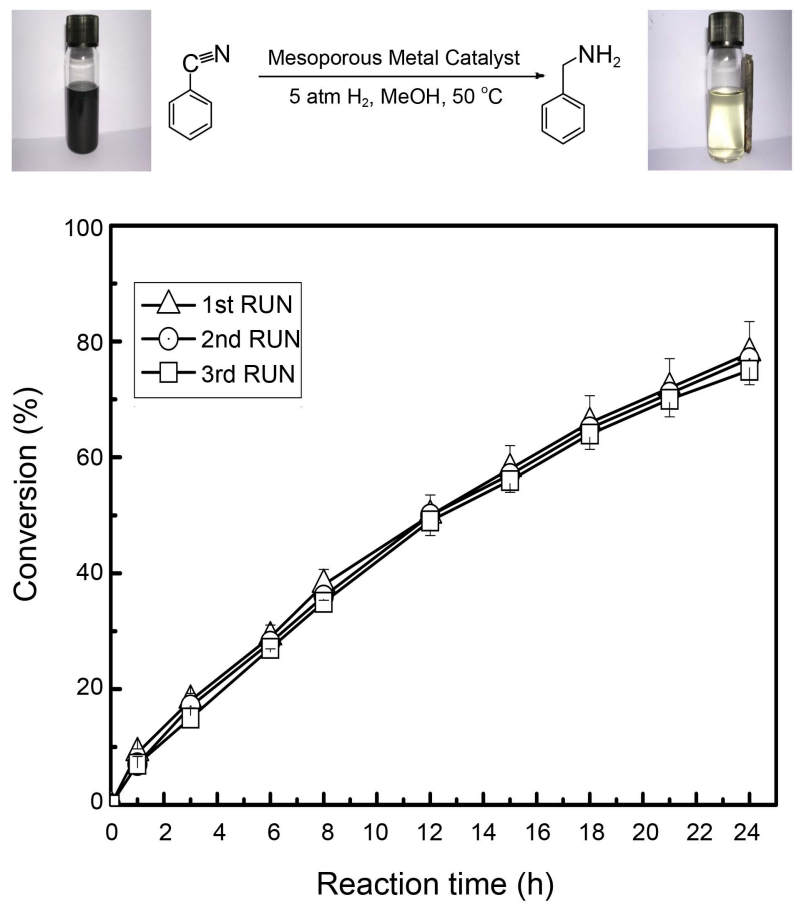

Figure 8. The recyclability of Ni microsphere metal in the hydrogenation of cyanobenzene to obtain the benzylamine.
Fig. 7. With increasing hydrogen pressure, the yields of product have increased at the same reaction time and temperature. The higher pressure of hydrogen more than 10 atm was not effective for the catalytic reduction. However under the low $\mathrm{H}_{2}$ pressure such as $3 \mathrm{~atm}$, the reductive reaction was very slow. This means that the adsorption of hydrogen on the metal is important to reduce the substrates. In this work, higher reaction temperature up to $85^{\circ} \mathrm{C}$ was essential to accelerate the reaction rates at the same $\mathrm{H}_{2}$ pressure. The conversion of cyanobenzene increased gradually as the reaction temperature has increased.

Recyclability of mesoporous Ni metal was investigated in the same reaction as performed above. The metal catalysts were collected by simple magnetic separation and washing with MC, THF solvents for reuse after completion of reaction. As shown in Figure 8, the metal particles could be easily separated from the reaction solution by a magnet. The catalysts could be reused efficiently in the hydrogenation of cyanobenzene to benzylamine, as summarized in Figure 8. After three times reuse, the hollow type nickel metal catalysts retained the almost same activity without a severe lose during the repeated use.

\section{Conclusion}

The hollow type mesoporous microcapsules of silica were fabricated by coating SBA-16 sol on the PVP modified PS. Additionally hollow $\mathrm{NiO}$ and $\mathrm{Co}_{3} \mathrm{O}_{4}$ mesoporous oxides were obtained through the reverse replication method. The mesoporous metals were employed as catalysts in the reduction of chiral butylronitrile and cyanobenzene to evaluate their catalytic activities. In the catalytic reduction, the mesoporous metals showed a higher activity than a nonporous metal powder and an impregnated metal on the carbon support.

Acknowledgments. This research was supported by Research grant of Inha University in 2011.

\section{References}

1. Caruso, F. Chem. Eur. J. 2000, 6, 413.

2. Kim, S. W.; Kim, M.; Lee, W.; Hyeon, Y. T. J. Am. Chem. Soc. 2002, 124, 7642 .

3. Jiang, P.; Berton, J. F.; Colvin, V. L. Science 2001, 291, 453.

4. Li, Y. S.; Shi, J. L.; Hua, Z. L.; Chen, H. R.; Ruan, M. L.; Yan, D. S. Nano Lett. 2003, 3, 609.

5. Xu, X.; Asher, S. A. J. Am. Chem. Soc. 2004, 126, 7940.

6. Wang, Y.; Cai, L.; Xia, Y. Adv. Mater. 2005, 17, 473.

7. Zhu, Y.; Shi, J.; Chen, H.; Shen, W.; Dong, X. Micro. Mesoporous Mater. 2005, 84, 218.

8. Caruso, F.; Schuler, C.; Kurth, D. G. Chem. Mater. 1999, 11, 3394.

9. Caruso, F.; Susha, A. S.; Giersig, Mohwald, M. H. Adv. Mater. 1999, 11,950 .

10. Caruso, F.; Shi, X.; Caruso, R. A.; Susha, A. Adv. Mater. 2000, 12, 950.

11. Lu, Y.; Fan, H.; Stump, A.; Ward, T.; Rieker, T.; Rinker, C. J. Nature 1999, 398, 223.

12. Gittins, D.; Caruso, I. F. Adv. Mater. 2001, 13, 740.

13. Huang, H.; Emsen, E. E.; Kowaleski, T.; Wooley, K. L. J. Am. 
Chem. Soc. 1999, 121, 3805.

14. Wang, X. D.; Yang, W. I.; Tang, Y.; Wang, Y. J.; Fu, S. K.; Gao, Z. Chem. Commun. 2000, 2161.

15. Zhong, Z.; Yin, Y.; Gates, B.; Xia, Y. Adv. Mater. 2000, 12, 206.

16. Putlitz, B. Z.; Landfester, K.; Fisher, H.; Antonietti, M. $A d v$. Mater. 2001, 13, 500.

17. Yoon, S. B.; Shon, K.; Kim, J. Y.; Shin, C. H.; Yu, J. S.; Hyeon, T. Adv. Mater. 2002, 14, 19.

18. Guo, X.-F.; Kim, Y.-S.; Kim, G. J. J. Phys. Chem. C 2009, 113, 8313.

19. Deng, Z.; Chen, M.; Zhou, S.; You, B.; Wu, L. Langmuir 2006, 22, 6403 .

20. Schmid, A.; Fujii, S.; Armes, S. P. Langmuir 2006, 22, 4923.

21. Imhof, A. Langmuir 2001, 17, 3579.

22. Ying, J. Y.; Mehnert, C. P.; Wong, M. S. Angew. Chem. Int. Edn. 1999, 38, 56.

23. Schth, F.; Schmidt, W. Adv. Mater. 2002, 14, 629.

24. Kresge, C. T.; Leonowicz, M. E.; Roth, W. J.; Vartuli, J. C.; Beck, J. S. Nature 1992, 359, 710 .

25. Asefa, T.; MacLachan, M. J.; Coombs, N.; Ozin, G. A. Nature
1999, $402,867$.

26. Garcia, C.; Zhang, Y. M.; DiSalvo, F.; Wiesner, U. Angew. Chem. Int. Edn. 2003, 42, 1526.

27. Mokaya, R. Angew. Chem. Int. Edn. 1999, 38, 2930.

28. Roucoux, A.; Schulz, J.; Patin, H. Chem. Rev. 2002, 102, 3757.

29. Kim, G. J.; Guo, X.-F. J. Phy. Chem. Sol. 2010, 71, 612.

30. Glaspell, G. P.; Jagodzinski, P. W.; Manivannan, A. J. Phys. Chem. B 2004, 108, 9604.

31. Matveev, V. V.; Baranov, D. A.; Yurkov, G. Y.; Akatiev, N. G.; Dotsenko, I. P.; Gubin, S. P. Chemical Physics Letter 2006, 422, 402.

32. Kumar, S.; Chakarvarti, S. K. J. Mat. Sci. 2004, 39, 3249.

33. Moises, C.; Pellicer, E.; Rossinyol, E.; Estrader, M.; LopezOrtege, A.; Nogues, J.; Castell, O.; Surinach, S.; Baro, M. D. J. Mat. Chem. 2010, 20, 7021.

34. Shi, Y.; Wan, Y.; Zhang, R.; Zhao, D. Adv. Funct. Mater. 2008, 18 , 2436.

35. Yue, W.; Zhou, W. J. Mat. Chem. 2007, 17, 4947.

36. Syukri; Ban, T.; Ohya, Y.; Takahashi, Y. Materials Chemistry and Physics 2003, 78, 645. 